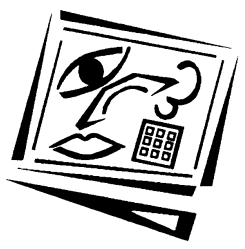

\title{
A constructivist learning experience: Reconstructing a web site using web based multimedia authoring tools
}

\author{
Ken T. K. Neo and Mai Neo \\ Multimedia University, Malaysia
}

\begin{abstract}
This paper focuses on using multimedia to create a constructivist learning experience as well as to innovate a multimedia mediated constructivist learning (MMCL) model based on a course given to students at the Faculty of Creative Multimedia, Multimedia University, Cyberjaya, Malaysia. Students were required reconstruct any existing website of their choice in the Internet that they thought required improvements. The purposes of the project were to assess problem solving skills and ability to evaluate a website's design, creativity and navigational structure. The students were required to enhance the site by adding sound and animation and to improve the overall look and feel of the site, using Web based multimedia authoring tools, Macromedia Dreamweaver and Flash. The course was structured for constructivist learning whereby students constructed their own knowledge of the project, determined their own learning outcomes, and worked in a collaborative and cooperative manner, thus taking an active part in the processes. A survey used to obtain feedback from the students indicated that using multimedia in a constructivist learning environment helped them to become more analytical and critical thinkers, more apt to seek information, and more motivated in their learning.
\end{abstract}

\section{Introduction: Learning perspectives}

As a whole, learning is a complicated and complex process. There are many theories that attempted to explain the learning process in the last century. During this period, the view on learning has changed in ways that have influenced significantly our educational practice and research. However, only three dominant views prevailed in the educational arena (Mayer, 1998). These views represent broadly the major trends in the way learning is conceptualised and provide some distinctively different guidelines for instructional practice (Orlich et. al, 1998).

In the first half of the century, the dominant view was the behaviourist perspective, which advocated that learning can be defined as an 
observable change of behaviour (Skinner, 1938). This model was the adaptation of the stimulus-response concept from psychological theory. Learning was considered as response acquisition and viewed as a mechanistic process in which successful responses are automatically strengthened and unsuccessful responses are automatically weakened according to environmental feedback. Within this view of learning, the learner is a passive recipient and the teacher is the active dispenser of knowledge and feedback, who rewards correct responses and punishes incorrect ones. Instruction focuses on increasing the number of correct behaviour in the learner's repertoire. 'Drill and practice' is the epitome of instruction in this behavourist movement (Mayer, 1998).

In the 1960s, the focus on learning research shifted from the strengthening and weakening of responses to the concept of acquisition of knowledge, i.e. from behaviourism to cognitivism. As a result, a second view of learning evolved. This cognitive view was based on the information processing theory in which the learner becomes a processor of information and the teacher becomes a dispenser of information. As the acquisition of knowledge became the focus of study, curriculum became the centre of instruction, and teaching basic information from textbooks and lectures became the focus of research and practice (Mayer, 1998). In this teachercentric mode, the teacher is regarded as the content expert and controls the instructional process and determines how much instructional content to be delivered to the learners. The aim of instruction is to increase the amount of knowledge acquired by the learner and the criterion of evaluation is by tests and examinations.

A third view of learning, the constructivist perspective, developed later. This view is rooted mainly in the works of Dewey, Bruner, Piaget, Vygotsky and Papert (Roblyer and Edwards, 2000), and has its foundations in cognitive learning psychology (Jonassen, Peck and Wilson, 1999, Oliver, 2000). In this perspective, the role of the learner changed from that of a recipient of knowledge to that of a constructor of knowledge, an autonomous learner with metacognitive skills for controlling his/her cognitive processes during learning (Mayer, 1998). This approach to learning emphasised that learning is active and occurs not by recording information but by interpreting it based on one's prior experiences. The hallmark of the model is that learners must construct what they learn and participate actively in their own learning process. Learning is contextual and is dependent on the shared understandings learners negotiate with their peers or teachers. The model emphasised that learners deepen their knowledge by shared experiences (Orlich, Harder, Callahan and Gibson, 1998). This mode of learning is considered as a student-centric instructional model whereby students determine their own learning needs, set their own goals, and monitor their own progress and 
determine how to reach the desired learning outcomes in a collaborative learning environment (Newby, Stephich, Lehman and Russell, 2000). The teacher is no longer perceived as the sole authority, but rather as the facilitator of learning, guiding and supporting learners in the process of constructing knowledge. The amount of guidance teachers provide depends on students' prior knowledge levels and experiences (Orlich et al, 1998). This constructivist process is geared towards determining how the student structures and processes knowledge rather than how much is learned (Mayer, 1998).

\section{Enhancing the learning environment}

In this project, we seek to develop a constructivist learning environment and to establish the elements that are likely to influence and enhance students' learning in this environment, by asking them to solve a multimedia design problem on the web i.e. to redesign their own selected websites using web based authoring tools. The websites were to be enhanced with multimedia and made interactive. In this context, the learning mode is student-centric. The students participated actively in their own learning process. They determined their learning goals and planned how to reach their learning outcomes themselves. In this constructivist mode, students will demonstrate their organising, planning and managing skills. In trying to solve a multimedia design problem, students will use their previously acquired knowledge on web design and multimedia and applying this multi-disciplinary knowledge to constructing new knowledge and solving problems that are realistically complex and personally meaningful. In the process, students will learn to become analytical and critical thinkers and problem solvers. This project will also enable the students to interact with their environment, be it their peers or teacher, and experience collaborative learning or working in groups to solve an authentic and realistic problem. The teacher will facilitate learning and act as a model and guide to knowledge construction by students. This shift towards the student-centric paradigm is significant and is redefining our concept of learning, the learner and the learning environment (Marshall,1998).

\section{Web based authoring tools : Macromedia Dreamweaver and Flash}

Authoring can be defined as integrating the different digital media elements such as text, graphics, sound, animation and video, into a coherent interactive application in a PC to convey a message or information (Neo \& Neo, 1997, Galbreath, 1992). Authoring tools are software packages that allow the user or author to perform the authoring process. Therefore, sound, video, graphics and animation files that are stored separately can be brought together into this special software to be 
mingled or integrated, sequenced and sychronised into a seamless application, and then delivered to the target audience via a CD-ROM or the Web (Figure 1).

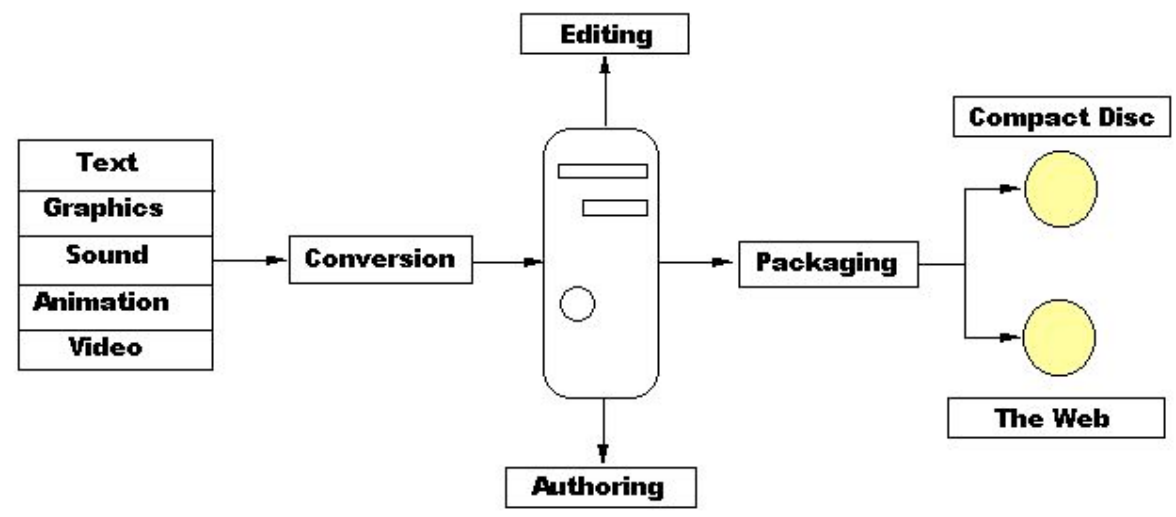

Figure 1: Process of authoring multimedia

There are several different types of authoring tools in the market today. They range from slide based authoring tools like Microsoft PowerPoint software to complex authoring tools such as Authorware and Director, and web based authoring tools such as Dreamweaver and Flash. Web authoring tools are software packages that contain all the characteristics of authoring tools but are geared towards Internet applications. Since the Internet is now a popular educational and information medium, many different web editor tools are available in the market. Two of the more popular tools are Macromedia Dreamweaver (Crowder \& Crowder, 2000) and Flash (Franklin \& Patton, 2000) which today have become industry standards for web page designers. They are very user friendly tools and many professional web designers select them as their tools of choice. As a whole, they complement one another: Dreamweaver allows users to create highly interactive web pages and Flash allows users to create highly dynamic web animation.

\section{Multimedia based projects: Creating a student-centric learning environment}

The evolution of multimedia has made it possible for learners to become involved actively in their work. With multimedia technologies, they can create multimedia applications as part of their project requirements. This makes them active participants in their own learning process, instead of just being passive learners of the educational content. This leads to a student-centric learning environment. In this learning environment, students can make use of the knowledge presented to them by the teacher, 
and represent them in a more meaningful way, using different media elements. These media elements can be converted into digital form and modified and customised for the final project.

To highlight this constructivist learning or student-centric experience (Caprariis, 2000), a multimedia design project was assigned to students during a multimedia course in their second year. The driving problem that the students need to address is the re-design of a badly designed web site on the Internet. Since most web sites are becoming more multimedia oriented, the students had to incorporate more than text and graphics into their web site to enhance it. The students were encouraged to harness their own abilities to use and appreciate media effectively when representing various pieces of information to convey a message to the audience. The students involved, however, have no previous exposure to working with a multimedia authoring tool, and in creating and managing multimedia project in a group setting. The advantage of creating multimedia projects in the classroom environment is that when students create multimedia projects, they tend to do this in a group environment. By working in a group situation, they will help motivate one another and work as team players to share ideas through inquiry and dialogue as well as to improve their thinking and social skills. There were no restrictions to what they can do as long as it was useful to enhance the overall message of the chosen web site. The only requirement was that they had to use Dreamweaver and Flash as their web authoring tools. Other supporting software such as Adobe PhotoShop, Adobe Premiere, Sonic Foundry's Sound Forge and other editing software were also permitted. At the end of the project, each group was to have a working prototype of their newly improved and enhanced web site.

\section{Conducting the class}

The class is based on a course in which students are taught to use specific web authoring tools, in this case, Macromedia Flash and Dreamweaver, and then to make use of these tools to solve a problem related to the Web. Although there are many commercial packages in the market that allow the users to create media rich and dynamic web pages, we used Macromedia Dreamweaver and Flash.

In this class, the lecturer's main function was to provide lectures and tutorials on the understanding of the Internet and multimedia technology and on the basic skills in using the software packages as well as web design. The students were given lectures that dealt with multimedia and the creation of multimedia presentations which provided the students with the fundamental concepts of the multimedia design process. This included deciding on the multimedia hardware and software, what was 
involved in creating a multimedia project, how media elements were gathered and modified, the creation of the presentation interface, and the use of interactivity in a multimedia presentation. The students were able to ask questions pertaining to the lecture at anytime during the course of the lesson. When it came to the students to implement their final project, the students will adopt a constructivist approach with the lecturer acting as a facilitator, guiding and supporting learners' own construction of knowledge." A guide on the side", so to speak.

As a group, the students had to decide on the concept of the presentation, the design of the presentation interface and navigation, and the appropriate digital multimedia elements and interactive features to use to best convey their topic of interest. The students used a suite of multimedia tools, particularly Macromedia Dreamweaver and Flash to design and reconstruct a website of their own choice for CD-ROM delivery. The students had the option of choosing their own team members and they were given the entire semester to develop the project.

Online communications: Yahoo Messenger

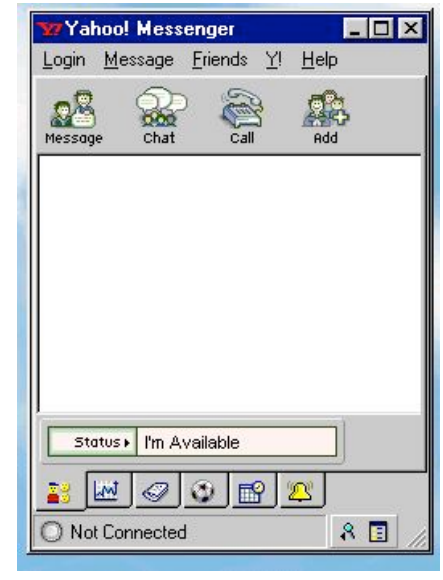

Figure 2: Yahoo! Messenger

During the course of the project, students were allowed and even encouraged to go to the lecturer to ask for guidance regarding their project. They could either make an appointment personally or as a group to see the lecturer or they could use the Internet to chat with the lecturer. Most of the students decided to use the Internet to communicate with the lecturer and to ask for help and guidance. 
The Internet tool that was used to provide this type of communication was the Yahoo Messenger (Figure 2). All the students had a unique Yahoo ID including the lecturer to allow for direct communications with the lecturer. It provided convenience for the students as the lecturer could provide answers and guidance over the Net very easily at anytime.

\section{Group presentation}

At the end of the project, each group is required to give a brief presentation on their project to the entire class and to answer questions posed to them by the lecturer or the students themselves. Each member of the group has to present his/her component task of the project and state the reasons for the improvements that were made to the original web site. By having them present their work, the students can authenticate their performances and their understanding of the project because they will have to provide explanation for their actions. Once the presentation was completed, each group had to turn in their work either on $\mathrm{CD}$ or Zip disks to the lecturer on time.

An example of the student's work is showcased below (the student's original language structure has been preserved for authenticity), and illustrated by Figure 3, Figure 4, Figure 5, Figure 6 and Figure 7.

\section{Student's work}

Choose a badly designed web site and plan how to make it better.

Name of the web site: Electric Pole 2000

Original Web site: http:/ / www.electripole.com/

Why is it a badly designed web page?

We choose this web site (see Figure 3) from a weird web site which

have a competition for the worst web site. It is the winner of April 2000.

(This web site is a personal web site that shows different pictures of electric poles taken throughout the United States. The creator travels the US throughout cities and countryside taking pictures of electric poles. He then compiles the pictures into this personal web site.)

\section{Criticism:}

1. Background: Unsuitable background with the content of page, this background image should not use title background, it just make the web site look untidy

2. Colour: The overall colour temperature is uncomfortable, not match with the function of the web site.

3. Link: Green colour link text is not suitable with background colour, it look deadly 
4. Graphics: The picture are in too dark colour, no thumbnails. The title of the main page is ugly.

5. Junk: Have 2 junky advertisements on the top and bottom of the page.

6. Table: The organisation of the main page, the button that used in sub pages are too big and uncomfortable.

7. Navigation: Because of the no thumbnails are used in this page, user has to wait for a long time download all the images in one category the image to get what they want.

8. General design: The focal point (title) is not strong enough, lack of contrast because of the title background. The main page is too long; the organisation of frame is not well.

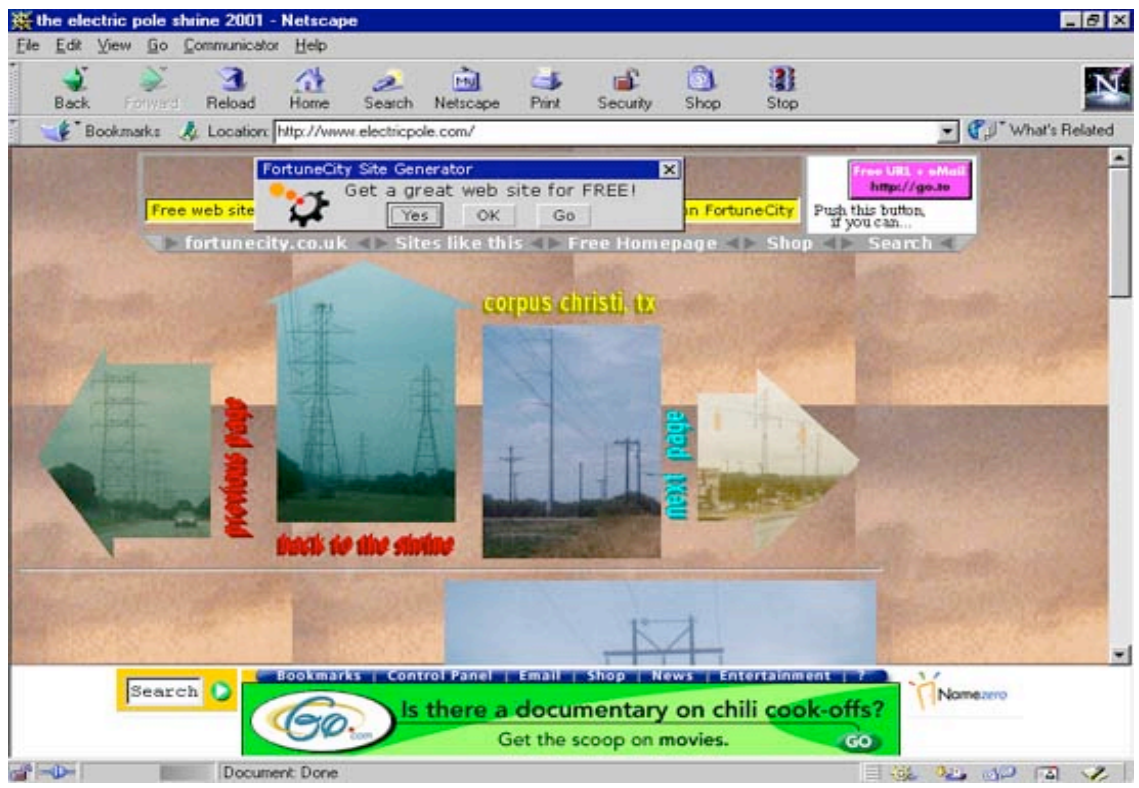

Figure 3: The original badly designed web site

Improvements:

1. Background: Just use blue colour for it is enough.

2. Colour: A comfortable set of colour for the images, font and buttons have been chosen to make it look more comfortable.

3. Font: Used bimini type font and bigger font size

4. Link: Now the colour of link is suitable with the background colour, the case of user cannot find the link text do not happen again. 
5. Graphics: The brightness of the images had been adjusted and the thumbnails are made. Suitable title for sub pages were made and a Flash movie is made for the intro.

6. Junk: The 2 junky advertisement on the top and the bottom had been thrown away.

7. Table: Reorganise the order of the table, make it easy to browse and find the information.

8. Button: Small button are using, mouse over effect are using to make the button easy to find out what it stand for

9. Navigation: Reorganise the order of the navigation so user can go back to main page and every 3 major sub pages easily. User also can browse through the picture category comfortable with new designed of navigation.

10. General design: We just make it simple, KISS=Keep It Simple Stupid. The overall design is using same style so users know that they are still in a same web site.

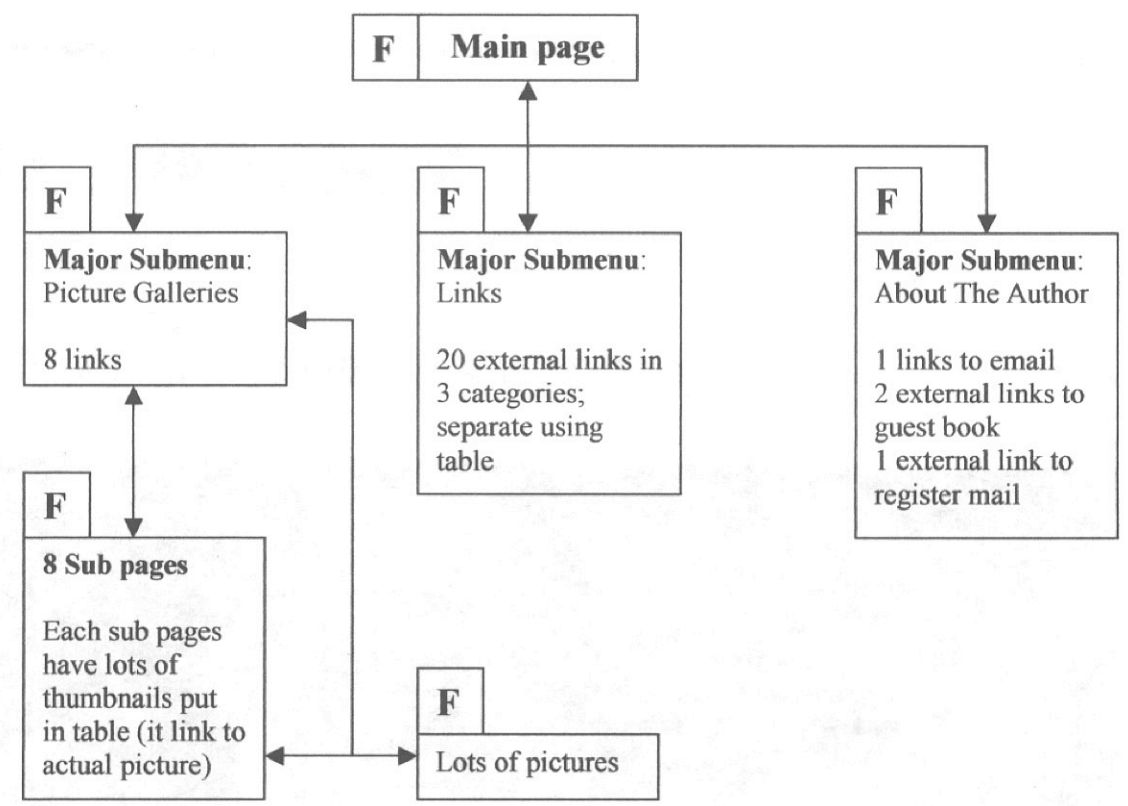

Figure 4: The website flowchart

(Legend: $\mathrm{F}$ indicates page with left frame, which can link to main page and also 3 major submenus) 


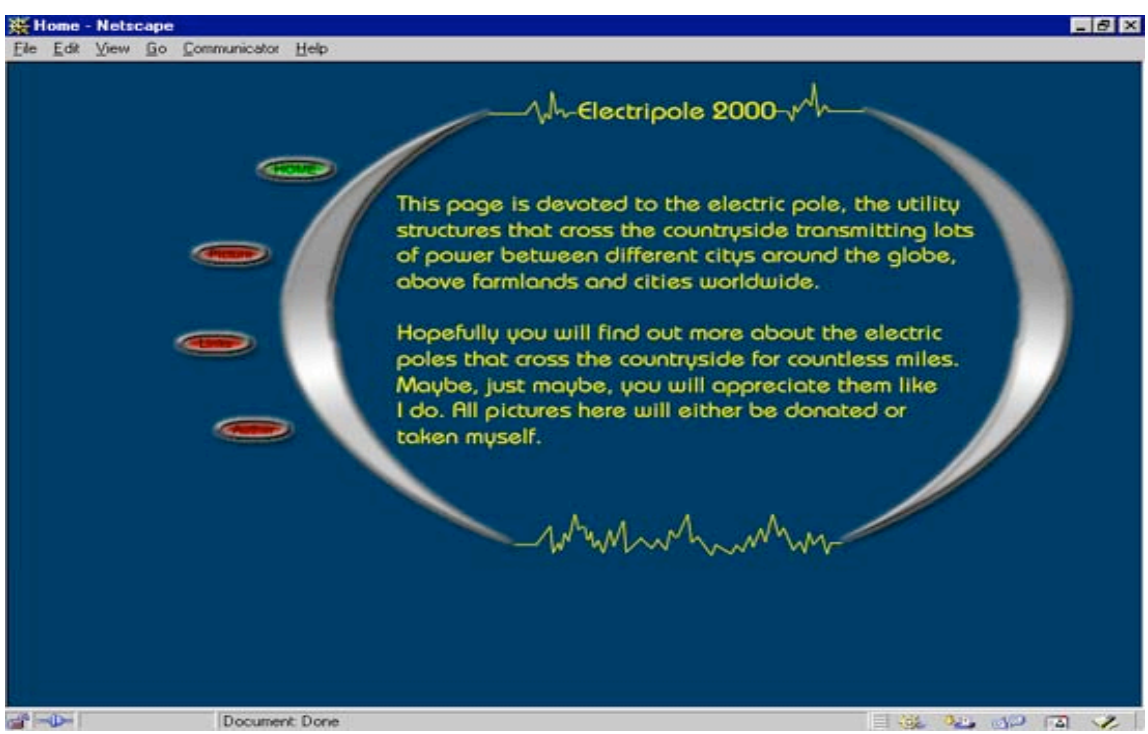

Figure 5: The Main Page or Home page of the modified web site. The buttons on the left, from top to bottom, are Home, Picture Galleries, Links and Author respectively.

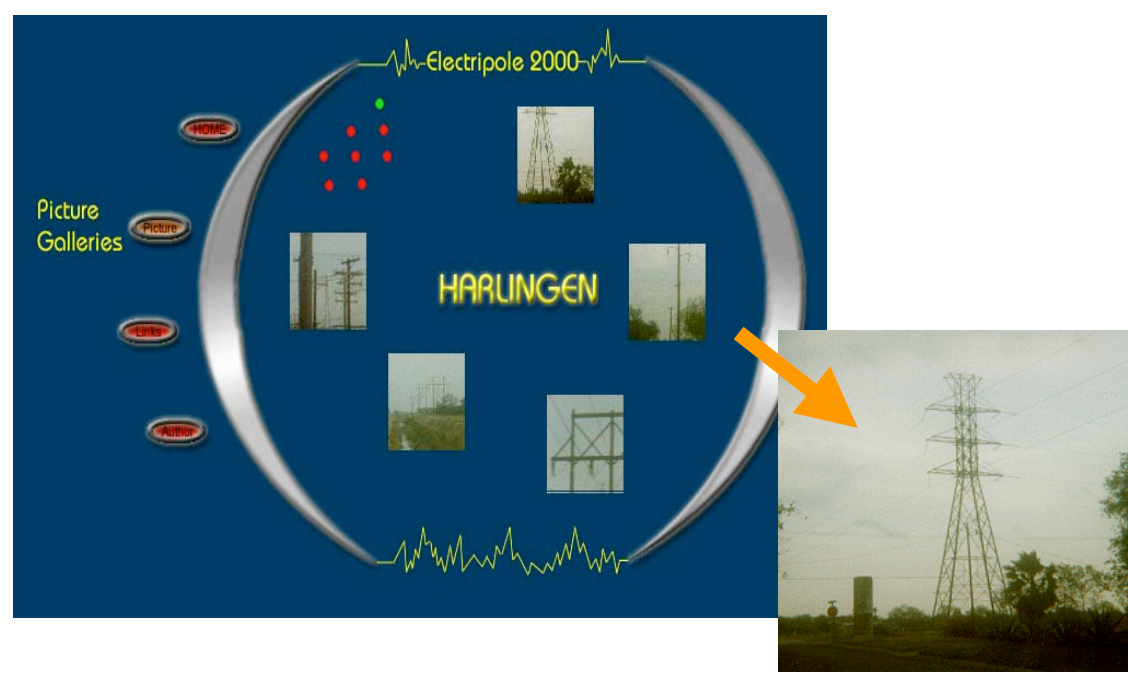

Figure 6: Picture Galleries - Harlingen Electric Poles. Arrow points to an enlarged picture of an electric pole in Harlingen 


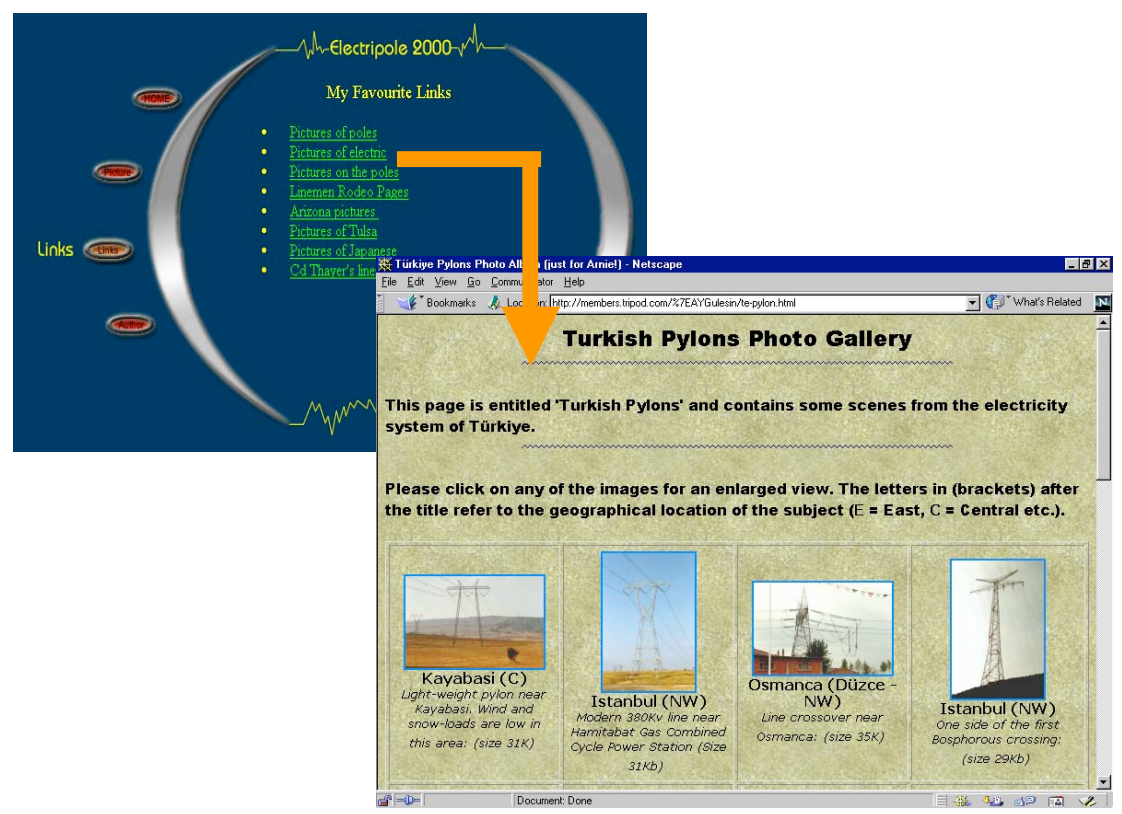

Figure 7: Inside the Links page. Arrow shows an example of a link (link \#2 on the Links page) to a related site on the Internet

\section{Project assessment}

The project was assessed based mainly on the following considerations:

1. Problem solving ability

- Students were judged on their ability to identify the problems or shortcomings of the web site.

- The students' suggested improvements and their implementation to reconstruct the web site.

2. Design and creativity

- The creative and innovative uses of Dreamweaver in creating interactive documents with clear navigational structure and proper working links.

- The creative and innovative uses of Flash in creating dynamic animations to enhance the communication of the message.

- The look and feel of the reconstructed web site as a whole

- User friendliness and pleasing graphical user interface. 
3. Teamwork

- The students' ability to work collaboratively in a group to select a web site, to organise the construction of the web site, to properly delegate work to each group member, and to provide consistency in designing the web pages.

4. Communicative and presentation ability

- The students' ability to effectively present their work and to answer questions from the class.

5. Motivation and discipline

- The students' ability to show that sufficient effort was attempted in the creation of the new web site.

- And the student's ability to follow guidelines and the timely submission of problem based report and the end project.

\section{Overall performance of the students}

In general, the students did well in this course. Of the total number of students in the class, $40 \%$ (41 out of 102) scored As, which is 80 points and above out of $100,58 \%$ (59 out of 102) scored Bs, and only $2 \%$ (2 out of 102) scored Cs. This was very encouraging as it indicates that by having them go through a constructivist learning environment, they were able to understand better the materials outlined in this course.

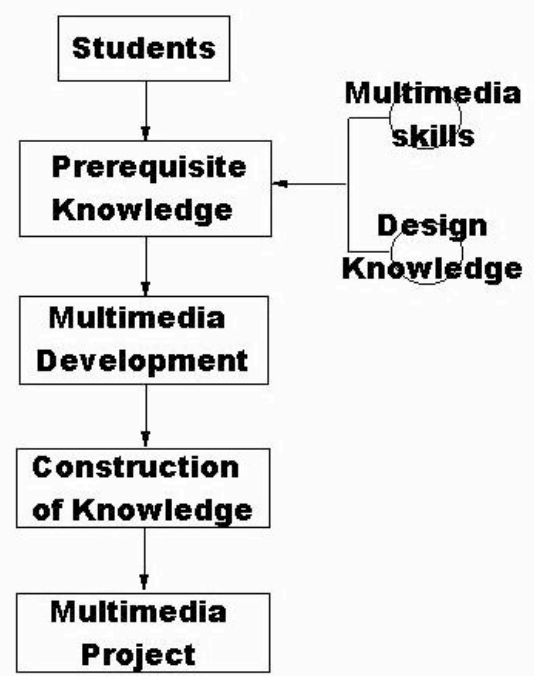

Figure 8: The multimedia mediated constructivist learning (MMCL) model 


\section{The multimedia mediated constructivist learning (MMCL) model}

During the course of this work, the learning experience was conceptualised into a schematic model as shown in Figure 8. This MMCL model summarises all the essential features of the learning experience and can serve as a vital guide in designing the constructivist learning process. It can also expose the students to multimedia design techniques and enhance their problem solving, creative and teamwork skills via authentic projects.

\section{Evaluating student learning}

At the end of the project, the students or respondents $(\mathrm{N}=102)$ were given a survey on their project. The survey questionnaire consisted of questions to assess the students' interest in group project work, and whether or not they were motivated in their project management. The survey also tried to gauge their level of understanding, their critical thinking skills as well as how they worked as a team. The survey was measured using a 5 point Likert scale, with 1 for Strongly Disagree (SDA), 2 for Disagree, 3 for Undecided, 4 for Agree and 5 for Strongly Agree (SA). These questions made up several constructs to measure the students' problem solving skills, collaborative efforts and teamwork. The data were analysed using SPSS (Statistical Package for Social Sciences) 10.0. The results were tabulated and their corresponding means are illustrated in Table 9.

Table 9. Means and percentages of students (ranked) $(\mathrm{N}=102)$

\begin{tabular}{|l|c|c|}
\hline \multicolumn{1}{|c|}{ Questions asked } & Mean & $\%$ \\
\hline 1. I knew exactly what my part was in the team & 3.91 & 83.2 \\
\hline 2. Project allowed me to be creative in my thinking & 3.89 & 82.4 \\
\hline 3. Team better able to present using digital media & 3.86 & 74.3 \\
\hline 4. I found the project challenging & 3.79 & 73.3 \\
\hline 5. I was able to have creative input & 3.79 & 71.6 \\
\hline 6. Project allowed me to think critically & 3.77 & 75.5 \\
\hline 7. Project enhanced understanding of the subject & 3.77 & 75.5 \\
\hline 8. Able to learn more working with teammates & 3.71 & 73.5 \\
\hline 9. Look forward to working on the project & 3.71 & 66.7 \\
\hline 10. Able to create project with existing software & 3.69 & 67.7 \\
\hline $\begin{array}{l}\text { 11. I understood the subject matter better after the } \\
\text { project development }\end{array}$ & 3.66 & 65.4 \\
\hline 12. Motivated doing project & 3.65 & 66.7 \\
\hline 13. Able to work as a team & 3.65 & 67.6 \\
\hline 14. Satisfied with own contribution in the project & 3.64 & 64.7 \\
\hline
\end{tabular}




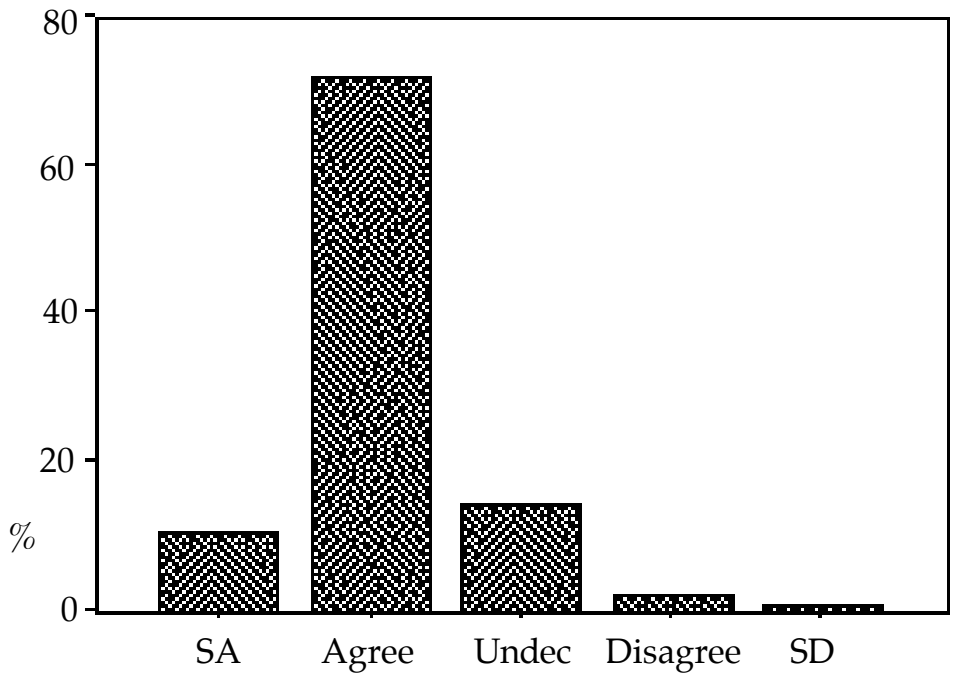

Figure 10(a): Project allowed me to be creative in my thinking

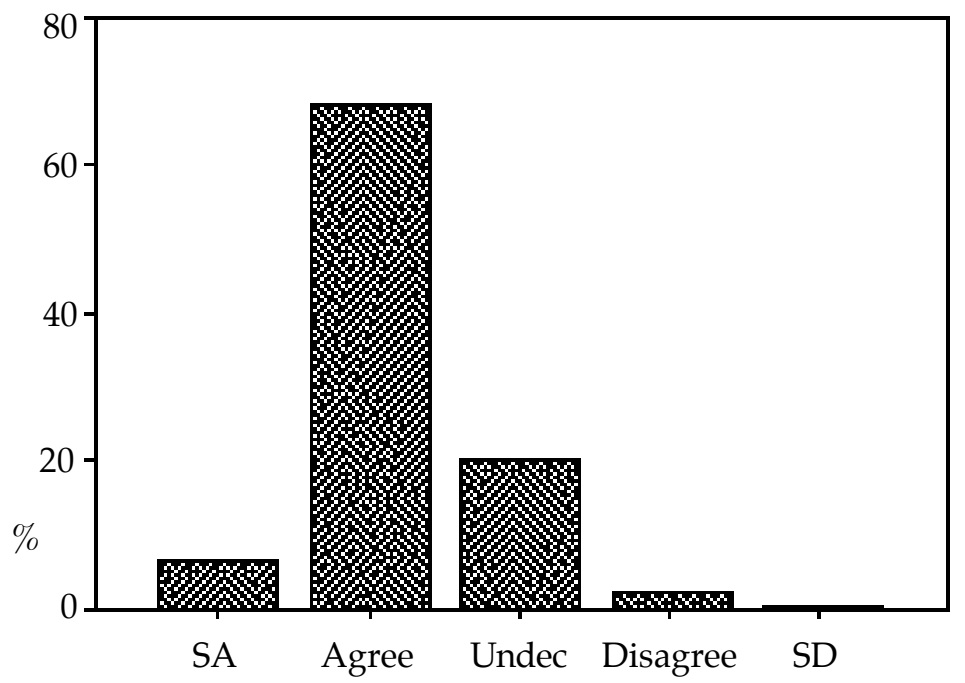

Figure 10(b): Project allowed me to think critically

Overall, the students responded well to the project given to them. Based on the survey taken, over $60 \%$ of the respondents were favourable toward the web based project. Over $70 \%$ of the students found that the project allowed them to be creative in their thinking $(82.4 \%$ respondents, with a 
mean of 3.89; see Figure $10(\mathrm{a})$ ), critical thinkers (75.5\% respondents, with a mean of 3.77, see Figure 10 (b)) and enhanced their understanding of the subject $(75.5 \%$ respondents, with a mean of 3.77$)$. In measuring teamwork, over $65 \%$ of the students responded favourably, with $83.2 \%$ stating that

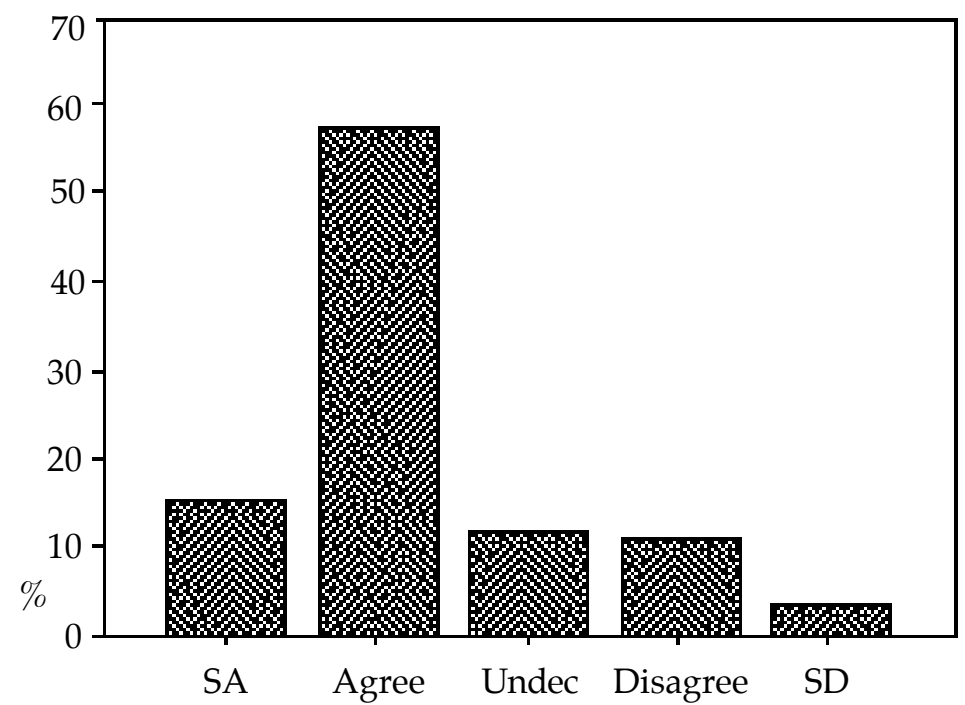

Figure 10(c): Able to learn more working with team mates

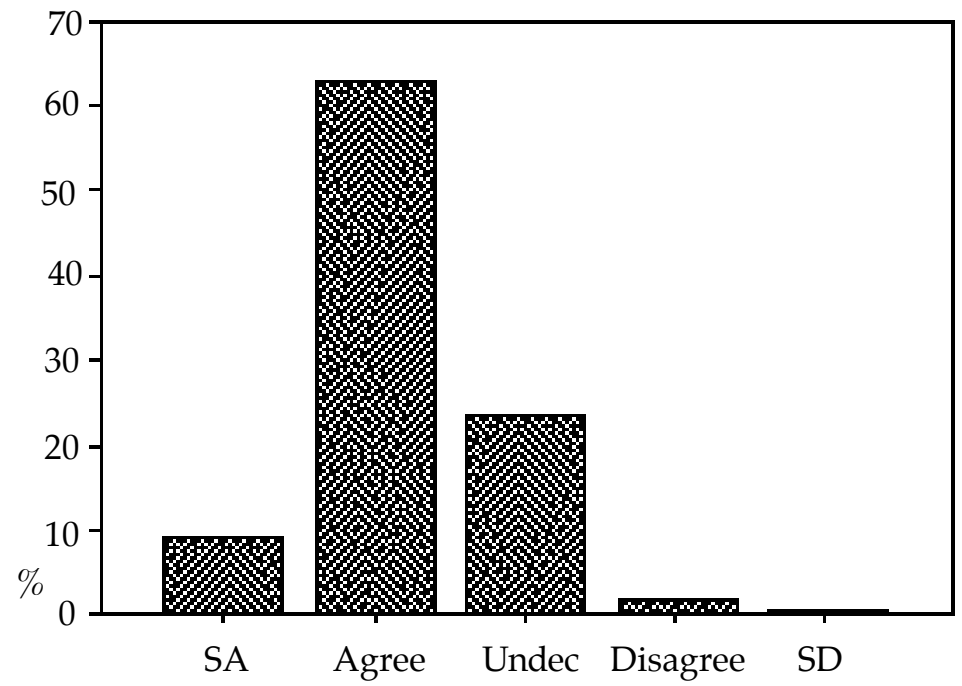

Figure 10(d): I found the project challenging 
they understood their part in the team (mean $=3.91), 74.3 \%$ stating that as the team was better able to present the information using digital media (mean $=3.86), 73.5 \%$ stating that they were able to learn more working with teammates (mean $=3.71$; see Figure $10(\mathrm{c})$ ), and $67.6 \%$ stating that they were able to work as a team (mean $=3.65$ ). Individually, these students found the project challenging $(73.5 \%$ with a mean of 3.79 ; see Figure 10(d)), looked forward to working on the project $(66.7 \%$ respondents, with a mean of 3.71), and were very motivated about doing the project ( $66.7 \%$ respondents, with a mean of 3.65$)$.

\section{Students' interviews and responses}

An interview with the students was also conducted using the chat room on the Internet. Table 11 lists some of the general comments made by students regarding the course on the constructivist learning mode.

From these remarks, we learnt the following from the students:

1. Learning technical software skills may be the easier part of the project as idea generating is challenging to them.

2. More heads are better than one, but working in a group is difficult. Each member has to learn tolerance and comprise when working in a group.

3. Group effort can solve a project's goals better than struggling alone.

4. Learning by doing makes one understand the subject matter better, encourages critical and analytical thinking and motivates one to seek information and solutions.

5. Project based learning makes one learn how to organise and to manage time appropriately, and how to apply previously acquired knowledge and experience to accomplish the project.

6. Project based learning improves students' communication skills, problem solving abilities and collaborative learning mindset and thus enhances their learning process.

7. The project enhances students' knowledge and trains them to work harmoniously together to seek information and solutions to a realistic problem. 
Table 11: Students' interviews

\begin{tabular}{|c|l|}
\hline No. & Comments from students \\
\hline 1. & $\begin{array}{l}\text { " We found the problem quite challenging. We have learned a lot } \\
\text { such as web publishing software, managing a website and what a } \\
\text { good website should be." }\end{array}$ \\
\hline 2. & " We learn to share ideas among the group and how to work together \\
efficiently."
\end{tabular}

\section{Discussion}

Multimedia is slowly gaining ground as a way for students to represent the knowledge that they acquire in class in multiple format and to construct their own interpretation of the information acquired. This MMCL environment was chosen because it allows the students to perform critical thinking by defining the problems of the site and to come up 
creatively with solutions to enhance the site on their own. Also, since the problem is authentic, students are able to draw from real life experiences to complete the task. By dividing them into groups, it also fosters collaborative and cooperative learning between and among students. They will learn to work together as a team and to learn from one another. This experience will thus better prepare them with a skill set for real life work situations and help them in their career later.

The results obtained both from students' performance as well as from their feedback were positive and encouraging. The students in general liked and enjoyed the constructivist approach to the multimedia oriented project. However, there were some problems associated with teamwork, scheduling and cooperation among some groups. Some of the feedback from their interviews contained comments pertaining to these conflicts and difficulties:

"Sometimes, we have communication problem, scheduling difficulty and the time is too short, so cannot get best work done."

" My group mates are not cooperative, so cannot finish part of the project. I rather work individually if no cooperative spirits exist among group members."

" All of us here are quite eager to express ourselves but is not easy to share my ideas and mix them with others. I think it is a tough project."

However, many of these difficulties and conflicts were solved in light of the overall project goals and through the leadership of the group leaders. All the groups were able to complete their projects on time and, the overall performance was satisfactory.

\section{Conclusion}

Our findings of the study show that the constructivist learning process using a multimedia project enhanced student learning in many ways and the MMCL model was strongly supported in this course, in that:

1. students were able to become active participants in their own learning, as evidenced by the modified presentation of information in the website, and were able to become reflective thinkers about their work, as demonstrated by their comments and depth of reflection on their projects.

2. in doing the project, students were highly motivated, actively immersed in managing and organising their own learning process, as well as work in a group as a team and learning from one another. Even though they faced difficulties in scheduling meetings and cooperation 
among members, they were able to solve them among themselves to complete the project.

3. we found that they enjoyed doing the project because it was meaningful to them as the problem was an authentic one and related to real life experiences. Students were able to draw from prior experiences in design and multimedia knowledge to better display the information in the chosen website.

4. in doing this project, multimedia technology became a driving force for enhancing the learning environment. Students looked forward to using the new technology as well as their existing ones for the creation of the project, and to provide them with more technical skills.

Multimedia also gave these students freedom of expression to be creative and represent their information in innovative ways. They were able to incorporate many more media elements in the website to make it more visually appealing, dynamic, and media rich.

5. by using multimedia in the teaching and learning environment, students are able to become analytical and critical thinkers, efficient problem solvers, more apt to seek information and more motivated in managing their learning processes.

6. we were able to move from playing a strictly teacher centred role to being more of a facilitator and a guide to them, thus promoting thinking on the part of the students.

7. students were trained to enhance their collaborative and problem solving skills to meet the needs of 21st century organisations.

8. the MMCL environment enhanced student learning by creating a student-centric learning mode.

These results served to demonstrate that in the constructivist learning mode, the students are the centre of the learning process, not the teacher, the content or the presentation. In this learning mode, the students are encouraged to take major responsibility for their own learning and participate actively in their own learning process. Knowledge is no longer something the students passively absorb, but rather something they actively construct or create. Thus, in the context of student-centric learning, the MMCL model innovated here serves as an effective guide to facilitate work in this area, and provide students with an opportunity to optimise their learning in an activity based learning environment. 
However, in order to successfully facilitate this type of learning environment, certain conditions have to be present. There must be sufficient hardware and software facilities for the students to be able to carry out their tasks. Computers and software packages for multimedia development must be made available. Faculty development towards the use of technology in the classroom and curriculum must also be cultivated in order to support this new way of teaching, whereby the technology is used by the teacher to support the curriculum and make them more effective guides and facilitators to the students' learning.

\section{References}

Caprariis, P. (2000). Constructivism in online learning: A view from the science faculty. Educational Technology, November-December, pp. 41-45.

Crowder, D. and Crowder, R. (2000). Mastering Macromedia Dreamweaver 3. SYBEX Inc. USA.

Franklin, D. and Patton, B. (2000). Flash 4! Creating Web Animation. Macromedia Press Inc. USA.

Galbreath, J. (1992). The educational buzzword of the 1990s: Multimedia, or is it hypermedia, or interactive multimedia, or ... ? Educational Technology, April, pp. 15-19.

Jonassen, D. H., Peck, K. L. and Wilson, B. G. (1999). Learning With Technology: A Constructivist Perspective. Prentice Hall, Inc. New Jersey, USA.

Marshall, H. H. (1998). Teaching educational psychology: Learner-centered and constructivist perspectives. In N. M. Lambert \& B. L. McCombs (Eds), How Students Learn: Reforming Schools Through Learner-Centered Education. American Psychological Association, Washington, DC, pp. 449-461.

Mayer, R. E. (1998). Cognitive theory for education: What teachers need to know. In N. M. Lambert \& B. L. McCombs (Eds), How Students Learn: Reforming Schools Through Learner-Centered Education. American Psychological Association, Washington DC, pp. 353-377.

Neo, M. \& Neo, K. (1997). The Multimedia Mosaic: Multimedia on the PC. Federal Publications Sdn. Bhd., (Times Publications Inc.), Selangor, Malaysia.

Newby, T. J., Stepich, D. A., Lehman, J., D. and Russell, J. D. (2000). Instructional Technology for Teaching and Learning: Designing Instruction, Integrating Computers, and Using Media (2nd Edition). Merrill/ Prentice Hall, New Jersey.

Oliver, K. M. (2000). Methods for developing constructivist learning on the Web. Educational Technology, November-December, pp. 5-18. 
Orlich, D. C., Harder, R. J., Callahan, R. C. and Gibson, H. W. (1998). Teaching Strategies: A Guide To Better Instruction. Houghton Mifflin Co., New York.

Roblyer, M. D. and Edwards, J. (1998). Integrating Educational Technology into Teaching (2nd edition). Merrill/ Prentice-Hall, New Jersey.

Skinner, B. F. (1938). The behavior of organisms. New York: Appleton.

Mr Ken T. K. Neo and Ms Mai Neo

Lecturers

Centre for Innovative Education (CINE)

Faculty of Creative Multimedia

Multimedia University

Cyberjaya, Selangor, Malaysia

Tel: +60 356357817 Fax: +60 356357817

Email: kneo@pc.jaring.my 